\title{
Novos editores da revista Medicina - Ribeirão Preto
}

m substituição a Júlio César
Voltarelli (Maria de Lourdes
Veronese Rodrigues - Editora) e José Alberto Mello de Oliveira (Eurico Arruda), em 12 de janeiro de 1999, juntamente com Orlando de Castro e Silva Júnior, que já fazia parte da gestão anterior, passamos a integrar a Comissão de Editoração da revista Medicina-Ribeirão Preto, para o biênio 1999-2001. Para a realização de nossas atividades continuaremos contando com a colaboração de Valderes Aparecida Coelho Falaschi (Secretária Geral) e Marlene Candida de Faria (Direção de Publicação).

Tradicionalmente esta revista está destinada a publicar textos que possam contribuir para a formação de estudantes de Medicina e para a Educação Continuada de Profissionais de Saúde. Uma das inovações que ocorreram nos últimos anos foi a introdução dos Simpósios, que têm tido avaliação altamente positiva. Pretendemos manter tudo isso e estimular a publicação de revisões por "experts", de introduções de teses e de artigos originais. Além disso, estaremos publicando "short-papers", relatos de casos originais, resenhas críticas, notas prévias, car- tas ao editor, pontos de vista e proposições teóricas e práticas. Os trabalhos poderão ser publicados em português e inglês ou espanhol.

A partir de 1997, o formato da revista foi modernizado e ela passou a receber apoio financeiro também da iniciativa privada. Infelizmente, agora, o principal patrocinador deixará de participar e necessitamos, com urgência, encontrar novas fontes de recursos.

Finalizando, agradecemos o apoio e a colaboração dos Profs. Drs. Júlio César Voltarelli e José Alberto Mello de Oliveira, que nos receberam nas reuniões da revista, durante o segundo semestre de 1998, desde as nossas indicações pela Congregação da Faculdade de Medicina de Ribeirão Preto e pelo Centro Acadêmico Rocha Lima. Agradecemos os ensinamentos e experiências que nos transmitiram e, também, a disponibilidade dos dois professores de continuar a nos ajudar. Esperamos manter o nível da Revista, continuando o excelente trabalho que fizeram.

Profa.Dra. Maria de Lourdes Veronese Rodrigues Prof.Dr. Eurico Arruda 